\title{
Acute Cholecystitis as a Cause of Fever in Aneurysmal Subarachnoid Hemorrhage
}

\author{
Na Rae Yang ${ }^{1,2}$, Kyung Sook Hong ${ }^{3}$, and Eui Kyo Seo ${ }^{1,2}$ \\ ${ }^{1}$ Department of Neurosurgery, Ewha Womans University Mokdong Hospital, Ewha Womans University School of Medicine, Seoul; ${ }^{2}$ Graduate School of Medicine, Ewha Womans \\ University, Seoul; ${ }^{3}$ Department of Surgery and Critical Care Medicine, Ewha Womans University Mokdong Hospital, Ewha Womans University School of Medicine, Seoul, Korea
}

Background: Fever is a very common complication that has been related to poor outcomes after aneurysmal subarachnoid hemorrhage (aSAH). The incidence of acalculous cholecystitis is reportedly $0.5 \%-5 \%$ in critically ill patients, and cerebrovascular disease is a risk factor for acute cholecystitis (AC). However, abdominal evaluations are not typically performed for febrile patients who have recently undergone aSAH surgeries. In this study, we discuss our experiences with febrile aSAH patients who were eventually diagnosed with AC.

Methods: We retrospectively reviewed 192 consecutive patients who underwent aSAH from January 2009 to December 2012 . We evaluated their characteristics, vital signs, laboratory findings, radiologic images, and pathological data from hospitalization. We defined fever as a body temperature of $>38.3^{\circ} \mathrm{C}$, according to the Society of Critical Care Medicine guidelines. We categorized the causes of fever and compared them between patients with and without AC.

Results: Of the 192 enrolled patients, two had a history of cholecystectomy, and eight (4.2\%) were eventually diagnosed with AC. Among them, six patients had undergone laparoscopic cholecystectomy. In their pathological findings, two patients showed findings consistent with coexistent chronic cholecystitis, and two showed necrotic changes to the gall bladder. Patients with AC tended to have higher white blood cell counts, aspartame aminotransferase levels, and C-reactive protein levels than patients with fevers from other causes. Predictors of $A C$ in the aSAH group were diabetes mellitus (odds ratio [OR], 8.758; $P=0.033$ ) and the initial consecutive fasting time $(\mathrm{OR}, 1.325 ; \mathrm{P}=0.024)$.

Conclusions: AC may cause fever in patients with aSAH. When patients with aSAH have a fever, diabetes mellitus and a long fasting time, AC should be suspected. A high degree of suspicion and a thorough abdominal examination of febrile aSAH patients allow for prompt diagnosis and treatment of this condition. Additionally, physicians should attempt to decrease the fasting time in aSAH patients.

Key Words: cholecystectomy; cholecystitis; intensive care units; prognosis; retrospective studies; subarachnoid hemorrhage.

Complications after aneurysmal subarachnoid hemorrhage (aSAH) account for significant patient morbidity and mortality; fevers, in particular, have been associated with poor outcomes [1,2]. In aSAH patients, fever increases cerebral edema and intracranial pressure, exacerbates ischemia, decreases the arterio-jugular oxygen content difference, and al-

\section{Received on October 10, 2016 Revised on February 27, 2017 Accepted on April 3, 2017 \\ Correspondence to: Eui Kyo Seo, Department of Neurosurgery, Ewha Womans University Mokdong Hospital, Ewha Womans University School of Medicine, 1071 Anyangcheon-ro, Yangcheon-gu, Seoul 07985, Korea}

Tel: +82-2-2650-2634, Fax: +82-2-2655-0948, E-mail: drekseo@ewha.ac.kr

*No potential conflict of interest relevant to this article was reported.

(c) This is an Open Access article distributed under the terms of the Creative Commons Attribution Non-Commercial License (http://creativecommons.org/ licenses/by-nc/4.0/) which permits unrestricted non-commercial use, distribution, and reproduction in any medium, provided the original work is properly cited. Copyright (c) 2017 The Korean Society of Critical Care Medicine 
ters levels of consciousness $[3,4]$. Infection can be identified as the cause of fever in approximately $75 \%$ of febrile aSAH patients [5] and is most frequently due to pneumonia, wound infection, sepsis, or urinary tract infection [3]; fever may also be due to thrombophlebitis, atelectasis, or allergic reactions. Determining the source of the febrile illness allows prompt therapy and improves the patient's prognosis.

The incidence of acalculous cholecystitis has been reported to be $0.5 \%-5 \%$ [6] in critically ill patients, and cerebrovascular disease is a risk factor for acute cholecystitis (AC) [7,8]. Glenn and Becker [9] also described one case of aSAH among 15 acalculous cholecystitis patients. However, little is known about the frequency of cholecystitis in patients with aSAH, and abdominal evaluations are not typically performed for febrile patients who have recently undergone aSAH surgeries. In this study, we discuss our experiences with febrile aSAH patients who were eventually diagnosed with AC.

\section{Materials and Methods}

We retrospectively reviewed the medical records and radiological findings of 192 consecutive patients hospitalized for aSAH, between January 2009 and December 2012. We evaluated the patient characteristics, neurologic and radiologic statuses (using the Hunt and Hess grade and Fisher classification), vital signs and laboratory data during hospitalization, pathological data, lengths of fasting prior to diagnosis, and hospital courses for these patients. Patients were evaluated for fever if they had a body temperature of $>38.3^{\circ} \mathrm{C}$, according to the Society of Critical Care Medicine guidelines [10]. Based on physical examinations, laboratory findings, and radiologic image studies, all patients with fever were categorized according to the fever's causes: lung problems, including pneumonia, atelectasis, and pleural effusion; catheter-related infections; operation-related infections, including cerebrospinal fluid infection and local wound infection; thrombophlebitis; drug fever; cholecystitis; in- flammation due to hemorrhage without infectious causes; pseudomembranous colitis bacteremia; and urinary tract infections. Laboratory studies, including white blood cell (WBC) counts, erythrocyte sedimentation rate, and serum levels of C-reactive protein (CRP), aspartame aminotransferase (AST), alanine aminotransferase, total bilirubin, and direct bilirubin were investigated. Patients with fever due to AC underwent percutaneous gallbladder drainage (PTGBD) or laparoscopic cholecystectomy (LC). PTGBD was performed by experienced interventional radiologists, and LC was performed by experienced general surgeons. AC diagnoses and treatment modalities were based on the decisions of the general surgeons after considering each patient's condition.

The characteristics of patients with and without AC were compared using the Student t-test. A one-way analysis of variance was used to compare the laboratory findings for each fever cause, and a forward conditional logistic regression analysis was used to determine predictors of AC in patients with aSAH. All statistical analyses were performed using SPSS version 20.0 (IBM Corp., Armonk, NY, USA) software package.

\section{Results}

Of the 192 aSAH patients admitted during the study period, including two with histories of cholecystectomies, eight ( $4.2 \%$; mean age, $66.29 \pm 11.59$ years [range, 57 to 79 years]) were eventually diagnosed with AC. Two patients underwent PTGBD, and six underwent LC.

During the study period, the incidence of fever was $79.7 \%(n=153)$ in the aSAH patients. Lung problems were the most common causes of fever (43.1\%). The incidence of non-infectious fever was $22.2 \%$. AC was the cause of fever in $5.2 \%$ of the 153 patients with fever (Table 1). In the analysis based on the cause of fever, WBC counts, AST levels, and CRP levels were significantly different between patients with and without AC (Table 2).

For febrile patients without AC, the mean first day of fever was hospital day $3.57 \pm 3.62$. The mean first day of 
fever for febrile patients with AC was hospital day 6.13 $\pm 2.17(\mathrm{P}=0.049)$. The mean initial consecutive fasting times for patients with and without $\mathrm{AC}$ were hospital day

Table 1. Causes of fever in patients with aneurysmal subarachnoid hemorrhage

\begin{tabular}{|c|c|}
\hline Cause & Incidence \\
\hline Lung problem ${ }^{\mathrm{a}}$ & $66(43.1)$ \\
\hline Inflammation due to non-infectious cause & $34(22.2)$ \\
\hline Catheter-related infection & $17(11.1)$ \\
\hline Operation-related infection ${ }^{c}$ & $11(7.2)$ \\
\hline Drug fever & $10(6.5)$ \\
\hline Acute cholecystitis & $8(5.2)$ \\
\hline Thrombophlebitis & $4(2.6)$ \\
\hline Others $^{d}$ & $3(2.0)$ \\
\hline
\end{tabular}

Values are presented as number (\%).

anclude pneumonia, atelectasis, pleural effusion, and pulmonary edema; 'Inflammation due to non-infectious causes may be due to intracranial hemorrhage; Include cerebrospinal fluid infection and local wound infection; Include urinary tract infections, pseudomembranous colitis, and bacteremia.
$5.38 \pm 2.78$ and hospital day $3.3 \pm 2.31$, respectively ( $\mathrm{P}$ $=0.014)$. The predictors of AC following aSAH were diabetes mellitus and the initial consecutive fasting time (Table 3).

Pathologic findings for the six patients who underwent LC are shown in Table 4. Their mean hospital stay was $54.3 \pm 24.5$ days (range, 30 to 89 days), and the mean intensive care unit stay was $26.8 \pm 8.5$ days (range, 17 to 37 days). On average, the patients underwent cholecystectomy after $24.5 \pm 12.4$ days (range, 16 to 47 days) of hospitalization. Each patient had a fever and leukocytosis at the time of diagnosis, and two had abdominal pain. Four patients demonstrated findings consistent with chronic cholecystitis, in addition to $\mathrm{AC}$, during their pathologic examinations, and two patients had necrotic gallbladders evident during surgery and the pathological examinations.

Table 2. Comparison of laboratory findings between patients with and without acute cholecystitis

\begin{tabular}{|c|c|c|c|c|c|}
\hline Variable & Acute cholecystitis & Mean \pm SD & Fever due to other causes & Mean \pm SD & P-value \\
\hline \multirow[t]{7}{*}{ WBC } & & $18,497.50 \pm 9,426.01$ & Lung problem & $11,651.23 \pm 3,766.27$ & 0.001 \\
\hline & & & Catheter-related infection & $13,259.41 \pm 4,468.37$ & 0.104 \\
\hline & & & Non-infectious cause & $11,282.06 \pm 4,335.04$ & 0.001 \\
\hline & & & Operation-related infection & $12,018.18 \pm 3,188.42$ & 0.036 \\
\hline & & & Drug fever & $9,703.00 \pm 2,611.47$ & 0.001 \\
\hline & & & Phlebitis & $12,477.50 \pm 2,326.83$ & 0.328 \\
\hline & & & Others & $9,000.00 \pm 7,014.98$ & 0.034 \\
\hline \multirow[t]{7}{*}{ AST } & & $61.63 \pm 63.81$ & Lung problem & $31.36 \pm 18.97$ & 0.017 \\
\hline & & & Catheter-related infection & $33.06 \pm 17.85$ & 0.090 \\
\hline & & & Non-infectious cause & $29.39 \pm 17.42$ & 0.017 \\
\hline & & & Operation-related infection & $31.40 \pm 14.82$ & 0.122 \\
\hline & & & Drug fever & $21.00 \pm 5.66$ & 0.022 \\
\hline & & & Phlebitis & $37.00 \pm 36.04$ & 0.671 \\
\hline & & & Others & $21.00 \pm 13.08$ & 0.175 \\
\hline \multirow[t]{7}{*}{ CRP } & & $9.25 \pm 10.87$ & Lung problem & $5.43 \pm 4.86$ & 0.460 \\
\hline & & & Catheter-related infection & $3.60 \pm 3.85$ & 0.167 \\
\hline & & & Non-infectious cause & $3.00 \pm 3.09$ & 0.043 \\
\hline & & & Operation-related infection & $4.80 \pm 3.46$ & 0.563 \\
\hline & & & Drug fever & $4.20 \pm 3.88$ & 0.395 \\
\hline & & & Phlebitis & $8.25 \pm 4.57$ & 1.000 \\
\hline & & & Others & $12.00 \pm 14.14$ & 0.997 \\
\hline
\end{tabular}

SD: standard deviation; WBC: white blood cell counts; AST: aspartame aminotransferase; CRP: C-reactive protein. 
Table 3. Logistic regression analysis results for predicting acute cholecystitis in aneurysmal subarachnoid hemorrhage

\begin{tabular}{lccccc}
\hline Variable & $\beta$ Coefficient & SE $\beta$ & Wald statistic & OR & P-value \\
\hline Initial consecutive fasting time & 0.282 & 0.125 & 5.078 & 1.325 & 0.024 \\
Diabetes mellitus & 2.170 & 1.016 & 4.564 & 8.758 & 0.033 \\
\hline
\end{tabular}

SE: standard error; OR: odds ratio.

Table 4. Pathologic findings of patients who underwent laparoscopic cholecystectomy

\begin{tabular}{lccl}
\hline Number & Age $(\mathrm{yr})$ & Sex & \\
\hline 1 & 76 & F & Chronic inflammation, erosion, gall stone $(-)$ \\
2 & 58 & F & Acute inflammation, chronic, gall stone $(+)$ \\
3 & 61 & F & Chronic inflammation, gall stone $(-)$ \\
4 & 57 & F & Acute inflammation, edema, fibrosis, gall stone $(-)$ \\
5 & 62 & F & Acute and chronic inflammation, necrotizing, gall stone $(+)$ \\
6 & 79 & F & Acute and chronic inflammation, mucosa necrotic appearance, gall stone $(-)$ \\
\hline
\end{tabular}

\section{Discussion}

Fever is a source of concern in aSAH patients, and it is associated with increased morbidity and mortality $[1,2]$. For eight patients in the present study, AC was ultimately determined to be the cause of fever. Previously, rare case reports have described the occurrence of $\mathrm{AC}$ in aSAH patients [11], including in one aSAH patient among 15 acalculous cholecystitis patients [9]. Additionally, some studies have suggested that cerebrovascular disease might be a risk factor for the occurrence of $\mathrm{AC}[7,8]$. To the best of our knowledge, this is the first study to evaluate $\mathrm{AC}$ as a medical complication during the treatment of aSAH.

In the present study, four of the six AC patients (66.6\%) pathologically proven had acalculous cholecystitis, whereas acalculous cholecystitis generally accounts for only $2 \%-15 \%$ of cholecystitis cases [12]. All eight of our patients had favorable condition grades and were diagnosed with AC following an evaluation for fever, leukocytosis, and abdominal pain during hospitalization in the neurological intensive care unit. Calculous cholecystitis is the result of gallstones blocking the flow of bile in the biliary tree, which leads to gallbladder inflammation [13]. The pathogenesis of acalculous cholecystitis is similar, but may be caused by bile stasis [14]. Bile stasis changes the chemical composition of bile and leads to gallbladder mucosal injury. Increases in bile lysophosphatidylcholine levels strongly influence functional water transport, and may cause gallbladder mucosa inflammation [15]. Other bile components, such as beta-glucuronidase, may also be involved in the pathogenesis of acute acalculous cholecystitis [16]. In our AC patients, the mean initial consecutive fasting period was $5.38 \pm 2.78$ days, suggesting that bile congestion occurred during the period leading to gallbladder distension and resulting in acute inflammation and cholecystitis [17].

Another mechanism leading to acalculous cholecystitis is the intense injury of blood vessels in the gallbladder muscularis and serosa [9] due to massive activation of the sympathetic nervous system in aSAH patients. This, then, leads to catecholamine-mediated injury [18,19]. At high concentrations, catecholamines directly damage the vascular endothelium, resulting in endothelial cell swelling, necrosis, and progressive de-endothelization [20,21]. Therefore, massive activation of the sympathetic nervous system, a feature of aSAH, could lead to acute acalculous cholecystitis.

Early enteral nutritional support for intensive care unit patients is known to improve their clinical outcomes [22] and is also known to improve the survival of aSAH patients [23]. Frequently, intracranial pressure-induced vomiting, persistent diarrhea, drug-related gastrointestinal mucosal inflammation, and ileus result in prolonged 
parenteral feeding of these patients. Considering that the reported incidence of acute acalculous cholecystitis during long-term total parenteral nutrition is $30 \%$ [24], acute acalculous cholecystitis may have occurred in our patients during their prolonged fasting period. In our study, the initial consecutive fasting time and the presence of diabetes mellitus were predictors for AC following aSAH. Furthermore, opioid analgesics [14] increase intraluminal bile duct pressure by causing sphincter of Oddi spasms. Therefore, the opioid analgesics administered to the aSAH patients may have also contributed to the onset of AC.

Persistent fever during this time could result in cerebral edema, increased intracranial pressure, exacerbation of ischemia, decreased arterio-jugular differences in oxygen content, and alteration in the level of consciousness that, in turn, would delay recovery [3,4]. Further, all of our patients had persistent fevers despite the use of antibiotics for $>3$ days. Because of the risks associated with persistent fevers in aSAH patients, we maintained a high degree of suspicion of cholecystitis, allowing prompt diagnoses and the provision of appropriate therapy. Computed tomography was found to be the most appropriate diagnostic tool for examining patients in the intensive care unit because it is not as operator-dependent as abdominal ultrasonography and requires less patient cooperation. Laparoscopic cholecystectomy was performed within 24 hours of diagnosis, in consultation with a general surgeon. PTGBD could have been performed instead of cholecystectomy, and two patients underwent PTGBD. These courses, chosen in consultation with a general surgeon, are supported by studies suggesting that early cholecystectomy is associated with decreased morbidity and cost [25]. In addition, two of our patients demonstrated necrotic gallbladder changes, making cholecystectomy the most appropriate treatment.

Although infections have been identified in $75 \%$ of febrile aSAH patients [5], our experience suggests infectious fever is the case of $71.3 \%$ of fevers in febrile aSAH patients. AC was the sixth leading cause of fever and the fourth leading cause of infectious fever in our study (Table 1). Thus, an evaluation for possible AC is indicated in any aSAH patient with a persistent fever that does not have an identified source. WBC counts, AST levels, and CRP levels are helpful for identifying cases with suspected AC, according to our results (Table 2). Prompt diagnosis and treatment may significantly affect the patient's prognosis.

Our study is limited by its retrospective design and single-center results. Nonetheless, it suggests the importance of recognizing $\mathrm{AC}$ as a cause of fever in aSAH patients. Because fever is a major medical complication for these patients, prompt determination of the source of the fever may reduce patient morbidity and mortality, and improve prognosis.

In conclusion, our study demonstrated the importance of maintaining a high degree of suspicion for the presence of AC as a cause of fever in aSAH patients. The presence of diabetes mellitus and the initial consecutive fasting time are predictors of AC in aSAH. Elevated WBC counts, AST levels, and CRP levels can help in distinguishing the cause of fever as AC. In addition, we suggest that early enteral nutrition and the avoidance of opioid analgesics may help prevent AC in aSAH patients.

\section{ORCID}

Na Rae Yang http://orcid.org/0000-0002-3226-5631

Kyung Sook Hong http://orcid.org/0000-0002-8022-5693

Eui Kyo Seo http://orcid.org/0000-0002-0541-9164

\section{References}

1. Naidech AM, Bendok BR, Bernstein RA, Alberts MJ, Batjer HH, Watts CM, et al. Fever burden and functional recovery after subarachnoid hemorrhage. Neurosurgery 2008;63:212-7.

2. Rosengart AJ, Schultheiss KE, Tolentino J, Macdonald RL. Prognostic factors for outcome in patients with aneurysmal subarachnoid hemorrhage. Stroke 
2007;38:2315-21.

3. Wartenberg KE, Schmidt JM, Claassen J, Temes RE, Frontera JA, Ostapkovich N, et al. Impact of medical complications on outcome after subarachnoid hemorrhage. Crit Care Med 2006;34:617-23.

4. Rossi S, Colombo A, Magnoni S, Roncati EZ, Conte V, Stocchetti N. Cerebral veno-arterial pCO2 difference as an estimator of uncompensated cerebral hypoperfusion. Acta Neurochir Suppl 2002;81:201-4.

5. Oliveira-Filho J, Ezzeddine MA, Segal AZ, Buonanno FS, Chang Y, Ogilvy CS, et al. Fever in subarachnoid hemorrhage: relationship to vasospasm and outcome. Neurology 2001;56:1299-304.

6. Mariat G, Mahul P, Prév t N, De Filippis JP, Cuilleron M, Dubois F, et al. Contribution of ultrasonography and cholescintigraphy to the diagnosis of acute acalculous cholecystitis in intensive care unit patients. Intensive Care Med 2000;26:1658-63.

7. Gu MG, Kim TN, Song J, Nam YJ, Lee JY, Park JS. Risk factors and therapeutic outcomes of acute acalculous cholecystitis. Digestion 2014;90:75-80.

8. Cho JY, Han HS, Yoon YS, Ahn KS. Risk factors for acute cholecystitis and a complicated clinical course in patients with symptomatic cholelithiasis. Arch Surg 2010;145:329-33.

9. Glenn F, Becker CG. Acute acalculous cholecystitis: an increasing entity. Ann Surg 1982;195:131-6.

10. O’Grady NP, Barie PS, Bartlett J, Bleck T, Garvey G, Jacobi J, et al. Practice parameters for evaluating new fever in critically ill adult patients: Task Force of the American College of Critical Care Medicine of the Society of Critical Care Medicine in collaboration with the Infectious Disease Society of America. Crit Care Med 1998;26:392-408.

11. Chang CW, Nagashima G, Fujimoto T, Suzuki R, Itokawa $\mathrm{H}$, Endoh $\mathrm{S}$, et al. Conspicuous endoscopic appearance of ventriculitis caused by coagulasenegative staphylococci. J Infect Chemother 2007;13: 177-9.

12. Fox MS, Wilk PJ, Weissmann HS, Freeman LM, Gliedman ML. Acute acalculous cholecystitis. Surg
Gynecol Obstet 1984;159:13-6.

13. Strasberg SM. Clinical practice: acute calculous cholecystitis. N Engl J Med 2008;358:2804-11.

14. Barie PS, Eachempati SR. Acute acalculous cholecystitis. Gastroenterol Clin North Am 2010;39:343-57.

15. Johnson EE, Hedley-Whyte J. Continuous positivepressure ventilation and choledochoduodenal flow resistance. J Appl Physiol 1975;39:937-42.

16. Kouroumalis E, Hopwood D, Ross PE, Milne G, Bouchier IA. Gallbladder epithelial acid hydrolases in human cholecystitis. J Pathol 1983;139:179-91.

17. Lin KY. Acute acalculous cholecystitis: a limited review of the literature. Mt Sinai J Med 1986;53:305-9.

18. Davison DL, Chawla LS, Selassie L, Tevar R, Junker C, Seneff MG. Neurogenic pulmonary edema: successful treatment with IV phentolamine. Chest 2012;141:793-5.

19. Wybraniec MT, Mizia-Stec K, Krzych Ł. Neurocardiogenic injury in subarachnoid hemorrhage: a wide spectrum of catecholamin-mediated brain-heart interactions. Cardiol J 2014;21:220-8.

20. Kristová V, Kriska M, Canová R, Hejdová E, Kobzová D, Dobrocký P. Endothelial changes following repeated effect of vasoconstrictive substances in vitro. Acta Physiol Hung 1993;81:363-70.

21. Makhmudov RM, Mamedov YaD, Dolgov VV, Repin VS. Catecholamine-mediated injury to endothelium in rabbit perfused aorta: a quantitative analysis by scanning electron microscopy. Cor Vasa 1985;27: 456-63.

22. Taylor SJ, Fettes SB, Jewkes C, Nelson RJ. Prospective, randomized, controlled trial to determine the effect of early enhanced enteral nutrition on clinical outcome in mechanically ventilated patients suffering head injury. Crit Care Med 1999;27:2525-31.

23. Norton B, Homer-Ward M, Donnelly MT, Long RG, Holmes GK. A randomised prospective comparison of percutaneous endoscopic gastrostomy and nasogastric tube feeding after acute dysphagic stroke. BMJ 1996;312:13-6.

24. Roslyn JJ, Pitt HA, Mann LL, Ament ME, Den- 
Besten L. Gallbladder disease in patients on longterm parenteral nutrition. Gastroenterology 1983;84: 148-54.

25. Gutt CN, Encke J, Köninger J, Harnoss JC, Weigand
K, Kipfmüller K, et al. Acute cholecystitis: early versus delayed cholecystectomy, a multicenter randomized trial (ACDC study, NCT00447304). Ann Surg 2013;258:385-93. 